\title{
Population Based Analysis Ependymoma Patients in Alberta from 1975 to 2007
}

\author{
Gloria B. Roldán Urgoiti, Amitabh D. Singh, Roger Y. Tsang, Robert A. Nordal, \\ Gerald Lim, Jennifer A. Chan, Yves P. Starreveld, Paula A. de Robles, \\ Bradly J. Biagioni, Mark G. Hamilton, Jacob C. Easaw
}

\begin{abstract}
Background: Ependymomas are rare tumors of the central nervous system whose management is controversial. This population-based study of adults and children with ependymoma aims to (1) identify clinical and treatment-related factors that impact survival and (2) determine if postoperative radiotherapy (RT) can improve survival of patients with subtotal resection (STR) to levels similar to patients who had gross total resection (GTR). Methods: This retrospective population-based study evaluated 158 patients with ependymoma diagnosed between 1975-2007 in Alberta, Canada. Results: Younger patients ( $<7$ years of age) were more likely to be diagnosed with grade III tumors compared with adults in whom grade I tumors were more common $(\mathrm{p}=0.003)$. Adults were more likely to have spinally located tumors compared to young children whose tumors were typically found in the brain. Overall, young children with ependymoma were more likely to die than older children or adults $(\mathrm{p}=0.001)$. An equivalent number of patients underwent GTR as compared with STR (48\% vs $45 \%$, respectively). Overall, older age, spinal tumor location, lower grade, and GTR were associated with improved progression free survival but only GTR was associated with significant improvement in overall survival. Median survival after STR and RT was 82 months compared with 122 months in patients who had GTR $(\mathrm{p}=0.0022)$. Conclusions: This is the first Canadian population-based analysis of patients with ependymoma including adults and children. Extent of resection appears to be the most important factor determining overall survival. Importantly, the addition of RT to patients initially treated with STR does not improve survival to levels similar to patients receiving GTR.
\end{abstract}

RÉSUMÉ: Analyse d'une population de patients atteints d'un épendymome entre 1975 et 2007 en Alberta. Contexte: Les épendymomes sont des tumeurs rares du système nerveux central dont le traitement demeure controversé. Le but de cette étude, portant sur une population d'adultes et d'enfants atteints d'un épendymome, était d'identifier les facteurs cliniques et thérapeutiques qui influencent la survie et de déterminer si la radiothérapie (RT) postchirurgicale peut améliorer la survie des patients qui ont subi une résection subtotale (RST) au point qu'elle soit similaire à celle des patients qui ont subi une résection large de la tumeur (RLT). Méthode: Cette étude rétrospective porte sur 158 patients atteints d'un épendymoma diagnostiqué entre 1975 et 2007 en Alberta, au Canada. Résultats: Un diagnostic de tumeur de grade III était plus fréquent chez les patients plus jeunes ( $<7$ ans) par rapport aux adultes chez qui des tumeurs de grade I étaient plus fréquentes $(\mathrm{p}=0,003)$. Les tumeurs étaient plus fréquemment localisées à la moelle épinière chez les adultes alors que chez les jeunes enfants les tumeurs étaient généralement localisées au cerveau. Les jeunes enfants atteints d'un épendymome étaient plus à risque de mourir que les enfants plus âgés ou les adultes $(\mathrm{p}=0,001)$. Un nombre équivalent de patients ont subi une RLT par rapport à une RST (48\% et $45 \%$ respectivement). En général, l'âge, la localisation de la tumeur à la moelle épinière, un grade inférieur de la tumeur et une RLT étaient associés à une meilleure survie sans progression, mais seule la RLT était associée à une amélioration significative de la survie globale. La survie médiane après une RST avec RT était de 82 mois par rapport à 122 mois chez les patients qui avaient subi une RLT ( $\mathrm{p}=0,0022)$. Conclusions: Il s'agit de la première étude portant sur une population de patients incluant des adultes et des enfants atteints d'un épendymome. L'étendue de la résection semble être le facteur le plus important de survie globale. À noter que la RT d'appoint chez les patients traités initialement par RST n'améliore pas la survie au point de la rendre égale à celle des patients qui ont eu une RLT.

Keywords: Ependymoma, radiation, population based study, retrospective, survival

doi:10.1017/cjn.2014.107

Can J Neurol Sci. 2014; 41: 742-747

Ependymomas are rare tumors of neuroectodermal origin arising from the central canal of spinal cord, filum terminale, choroid plexus and ependymal cells of the cerebral ventricles. The World Health Organization (WHO) classification of central nervous system (CNS) tumors stratifies ependymomas according to grade. Grade I lesions include myxopapillary ependymoma and subependymoma, grade II lesions include cellular, papillary, clear cell and tanycytic ependymoma and anaplastic ependymomas are grade III. ${ }^{1}$ Intracranial ependymomas represent $6-9 \%$ of primary CNS neoplasms and account for $30 \%$ of primary CNS tumors in children younger than 3 years. ${ }^{2}$ In the spinal cord, ependymomas are the most common neuroepithelial neoplasms, comprising $50-60 \%$ of spinal gliomas. ${ }^{1,3}$

From the Department of Medicine (GBR); Department of Medical Oncology (GBR, ADS, RYT, BJB, JCE); Department of Radiation Oncology (RAN, GL), Tom Baker Cancer Centre; Departments of Pathology and Laboratory Medicine, Clinical

Neurosciences, and Oncology (JAC); Division of Neurosurgery (YPS, MGH); Division of Neurology (PAD), Department of Clinical Neurosciences, University of Calgary, Alberta, Canada.

Received August 6, 2014. Final Revisions Submitted October 15, 2014 Correspondence to: Jacob Easaw, Tom Baker Cancer Centre, 133129 St NW, Calgary, AB, Canada T2N 4N2. Email: jay.easaw@albertahealthservices.ca 
The management of these patients is controversial and the identification of prognostic and predictive factors for survival and recurrence is an area of ongoing research. Most clinicians accept that maximal safe surgical resection is optimal where possible. At present, no chemotherapeutic regimen consistently increases survival. $^{4,5}$ There is clinical equipoise regarding the role of radiotherapy (RT) with some studies suggesting benefit ${ }^{3-7}$ and others reporting no clear advantage. ${ }^{8,9}$ Specifically, it is unclear whether the addition of RT can improve the survival of a patient with an subtotal resection (STR) to levels similar to patients who have had a gross total resection (GTR). Furthermore, it is not clear if other factors such as age, gender, location, extent of surgical resection, and pathological grade influence the ability of radiation to improve survival. ${ }^{4,10-13}$

In this study, we report the results of a large population-based study including all cases of ependymoma diagnosed over a 32 year period in the province of Alberta, Canada. Our two objectives were to (1) identify clinical and treatment factors that affect recurrence and survival in patients diagnosed with ependymoma and (2) determine if the addition of postoperative radiotherapy can make up for incomplete surgery and improve the survival of patients treated with STR to levels comparable to those who have GTR.

\section{Methods}

This retrospective population based study included every patient diagnosed with ependymoma between December/1975 and July/2007 in the province of Alberta, Canada. One hundred eighty patients were identified from the Alberta Cancer Registry and clinicopathological data was retrieved from the patients' charts (Figure 1). In ten cases where the pathological description was ambiguous with respect to tumor classification, a neuropathologist (JC) performed secondary review of the specimen (six cases) or pathological report (four cases) if the specimen was not available. From this initial cohort, 158 patients were included for the final analysis. Seventeen patients were excluded because the diagnosis was made radiologically in the absence of histopathology or tumors that would not be classified as ependymoma

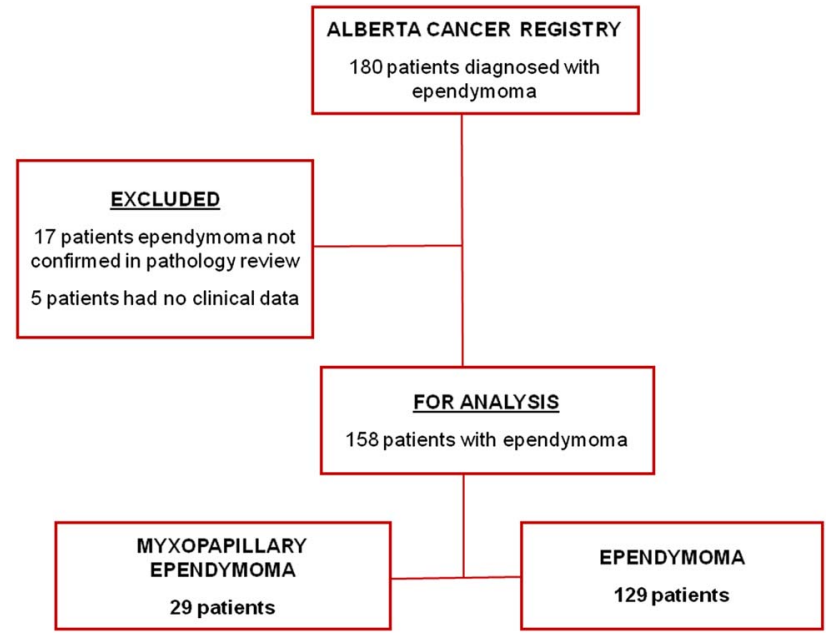

Figure 1: Flowchart of patients diagnosed with ependymoma in Alberta, from 1975 to 2007. according to the WHO classification of tumors of the CNS. ${ }^{1}$ Five additional patients were excluded due to the lack of clinical data. Study approval was obtained from the University of Calgary Conjoint Health Research Ethics Board.

\section{Clinical and Statistical Considerations}

Age ranges were defined as 0-6, 7-17, 18-50 and greater than 50 years old. Tumor location was catergorized as spinal, supratentorial or infratentorial. The extent of resection was based on postoperative imaging $(\mathrm{n}=85 ; 71 \%)$ or the surgeon's intraoperative impression $(n=35 ; 29 \%)$ where imaging was not available. In nine cases the extent of resection could not be determined. Gross total resection was classified as complete resection of the mass. Any resection with residual lesion was classified as STR. Progression-free survival (PFS) was defined as the interval between diagnosis and time to when the patient recurred/ progressed, died (events) or was lost to follow up (censored data point). Overall survival (OS) was calculated from date of diagnosis to death or lost to follow-up. Results were tabulated and analyzed with STATA/OC 12. Two-tailed Chi-squared or Fisher's exact tests were used to determine the significance of associations between proportions. Clinical variables were evaluated for association with survival using Cox proportional hazards model and Kaplan-Meier survival analysis with log-rank test. Variables with significance in univariate analysis $(\mathrm{p}<0.05)$ were included in multivariate regression.

\section{ReSUlts}

\section{Myxopapillary ependymomas}

Myxopapillary ependymomas comprised $18 \%$ of the patients (29/158). The median age at diagnosis was 33 years and 14 were female $(48 \%)$. Five patients were younger than 18 years $(17 \%)$ and 24 were adults $(83 \%)$. All but one tumor (28/29) was located in the spine, except for one case of concurrent supratentorial and spinal lesions (both resected and confirmed to be myxopapillary ependymomas). Eleven (38\%) were subtotally resected and 14 had GTR. The extent of resection was unknown in four cases. Postoperative radiotherapy was administered in 73\% (8/11) and $14 \%(2 / 14)$ of the patients with STR and GTR, respectively. Recurrent disease was noted in five patients. The majority of these patients $(n=4)$ had STR of which two received postoperative RT. Only two patients with myxopapillary tumors died in this series after survivals of 66 and 158 months; median progression-free survival (PFS) and overall survival (OS) were 95 and 108 months, respectively. Neither age, location, nor initial treatment was associated with progression-free or overall survival in this group. Patients with myxopapillary ependymomas had longer survival compared to the 129 patients with other ependymoma in this series $(\mathrm{p}=0.017$ and $\mathrm{p}=0.0082$ for PFS and OS, respectively).

\section{Relationship Between Clinical Factors (Gender, Age, Grade, Tumor Location) to Progression and Survival}

Excluding patients with myxopapillary ependymoma, 129 patients were included for subsequent analysis. Patient characteristics are summarized in Table 1. Patient gender did not correlate with any clinical/prognostic variable, although most patients under the age of $18(69 \%)$ were male $(31 / 45 ; \mathrm{p}=0.037)$. 
Table 1: Characteristics of 129 patients with ependymoma diagnosed in Alberta between 1975 to 2007

\begin{tabular}{|c|c|c|}
\hline Characteristics & $\mathbf{n}$ & $\%$ \\
\hline \multicolumn{3}{|l|}{ Gender } \\
\hline Male & 73 & 59 \\
\hline Female & 56 & 41 \\
\hline \multicolumn{3}{|l|}{ Age } \\
\hline Up to 6 years & 31 & 26 \\
\hline $7-17$ years & 14 & 11 \\
\hline $18-50$ years & 48 & 34 \\
\hline More than 50 years & 36 & 29 \\
\hline \multicolumn{3}{|l|}{ Location of tumor } \\
\hline Supratentorial & 21 & 16 \\
\hline Infratentorial & 62 & 52 \\
\hline Spine & 46 & 32 \\
\hline \multicolumn{3}{|l|}{ Extent of surgical resection } \\
\hline Gross total resection & 62 & 48 \\
\hline Subtotal resection & 58 & 45 \\
\hline Unknown & 9 & 7 \\
\hline \multicolumn{3}{|l|}{ Pathological grade } \\
\hline WHO grade I & 11 & 9 \\
\hline WHO grade II & 106 & 82 \\
\hline WHO grade III & 11 & 9 \\
\hline Unknown & 1 & 0.7 \\
\hline \multicolumn{3}{|l|}{ Initial Treatment } \\
\hline Subtotal Resection & 21 & 16 \\
\hline Subtotal Resection $\pm \mathrm{RT}$ & 37 & 29 \\
\hline Gross-total Resection & 42 & 33 \\
\hline Gross-total Resection $\pm \mathrm{RT}$ & 20 & 15 \\
\hline Unknown & 9 & 7 \\
\hline
\end{tabular}

WHO = World Health Organization; RT = Radiotherapy

Patients up to the age of six years were more likely to progress (23/51 total recurrences; $\mathrm{p}<0.0001)$ and die $(18 / 45$ total deaths; $\mathrm{p}=0.001)$ compared with older patients. Age was associated with tumor location $(\mathrm{p}<0.0001)$ as children up to six years old had tumors supra- or infratentorially $(90 \% ; 28 / 31)$ while only three patients $(10 \%)$ in this age range had spinal tumors. Patients between the age of 7-17 were more likely to have infratentorial tumors $(n=8 / 14)$. In adults, 26 of the 48 patients between ages of 18 and 50 years old $(54 \%)$ had spinal tumors and those older than 50 usually had infratentorial and spinal-located tumors (17/36 and $15 / 36$, respectively).

Grade I $(\mathrm{n}=11)$ and III tumors $(\mathrm{n}=11)$ were more likely to be distributed either supra- or infratentorially but rarely in the spinal cord whereas Grade II lesions $(n=106)$ were present throughout the CNS comprising $40 \%$ of all supratentorial lesions, $85 \%$ of all infratentorial lesions and $98 \%$ of spinal tumors. In this series histological grade was associated with tumor location ( $p<0.0001)$ but the predominance of Grade II tumors, as described above, may bias the analysis.
We identified a statistically significant association between age group and histological grade. The youngest patients ( $0-6$ years old) were more likely to be diagnosed with grade III lesions whereas every incidence of grade I tumors were seen in adults $(p=0.003)$. In this series, age was not associated with differences in either the extent of resection or the addition of postoperative radiotherapy.

\section{Radiation Therapy}

Sixty-three patients $(49 \%)$ did not receive postoperative radiotherapy as part of their initial management, whereas 57 patients (44\%) received RT following surgery. Radiation therapy was administered to the local tumor in 42 cases and to the tumor and cranio-spinal axis in 15 cases. There was evidence of leptomeningeal spread in pre- or post-operative images in only five patients, of which two received cranio-spinal RT. In ten cases, RT was given after the first recurrence and one patient received RT twice. Chemotherapy was administered only in six patients; all of them had grade II infratentorial lesions and median age was 1.5 years years-of-age (range; 0.5 to 7.7 years old).

Sixty-two patients underwent GTR of the tumor (48\%), 58 had a STR $(45 \%)$ and the extent of tumor resection was unknown in 9 patients. The extent of initial surgery was not associated with age, location or histological grade.

Following STR, 64\% (37/58) of patients received radiotherapy. The decision to deliver radiotherapy was dependent on the extent of surgery and grade. Tumor location did not seem to impact the delivery of radiotherapy, however, tumor grade was important with only $9 \%$ of grade I tumors receiving adjuvant RT compared with $72 \%$ and $60 \%$ of grade II and III tumors, respectively $(\mathrm{p}=0.029)$. After GTR, only $11 \%$ (1/9) supratentorial ependymoma and $4 \%$ $(1 / 22)$ spinal tumor received radiation, compared with $58 \%(18 / 31)$ of infratentorial tumors $(p=0.002)$. Radiotherapy was administered after GTR in $31 \%$ (16/51) of patients with grade II tumors and $67 \%(4 / 6)$ patients with grade III tumors.

\section{Progression Free Survival}

Median progression-free survival was 55 months for all patients. Table 2 includes univariate analysis for PFS with Hazard Ratio (HR) (95\% CI) and p values for each variable. For those patients younger than seven years, the median PFS was 20 months. This was significantly worse compared with 58,83 and 63 months for patients between 7-17 years $(p=0.034), 18-50$ years $(\mathrm{p}<0.0001)$ and greater than 50 years of age $(\mathrm{p}<0.0001)$, respectively.

\section{Tumor location and grade impacted PFS}

Patients with supratentorial tumors had a decreased median PFS of 19 months compared with infratentorial (55 months) and spinal (77 months) lesions ( $\mathrm{p}=0.074$ and $\mathrm{p}<0.0001$, respectively). Histological grade I and II tumors had median PFS of 75 months and 56 months, respectively $(\mathrm{p}=0.256)$. Not unexpectedly, PFS for grade I tumors was significantly better than those with grade III lesions ( 15 months) $(\mathrm{p}=0.005)$.

Patients with GTR had an improved median PFS (71 months) compared with 37 months for those receiving subtotal resection $(p=0.0161)$. Importantly, the addition of radiotherapy did not improve PFS following STR $(p=0.62)$ or GTR $(p=0.67)$. 
Table 2: Univariate analysis for Progression Free Survival (PFS) and Overall Survival (OS) of 129 patients with ependymoma (excluded myxopapillary)

\begin{tabular}{|c|c|c|c|c|}
\hline Variable & $\begin{array}{c}\text { PFS HR } \\
(95 \% \text { CI })\end{array}$ & $\begin{array}{c}\text { PFS } \\
\text { p-value }\end{array}$ & $\begin{array}{c}\text { OS HR } \\
(95 \% \text { CI })\end{array}$ & $\underset{\text { p-value }}{\text { OS }}$ \\
\hline \multicolumn{5}{|l|}{ Age range (years) } \\
\hline 0 to $<6$ & 1.00 & & 1.00 & \\
\hline 7 to 17 & $0.38(0.15-0.93)$ & $0.034^{\mathrm{a}}$ & $0.40(0.13-1.1)$ & 0.076 \\
\hline $18-50$ & $0.21(0.11-0.42)$ & $<0.0001^{\mathrm{a}}$ & $0.15(0.06-0.37)$ & $<0.0001^{\mathrm{a}}$ \\
\hline$>50$ & $0.21(0.09-0.45)$ & $<0.0001^{\mathrm{a}}$ & $0.55(0.28-1.09)$ & 0.09 \\
\hline \multicolumn{5}{|l|}{ Location } \\
\hline supratentorial & 1.00 & & 1.00 & \\
\hline infratentorial & $0.54(0.27-1.06)$ & 0.074 & $0.95(0.42-2.11)$ & 0.896 \\
\hline spinal & $0.22(0.09-0.50)$ & $<0.0001^{\mathrm{a}}$ & $0.54(0.22-1.32)$ & 0.176 \\
\hline \multicolumn{5}{|l|}{ WHO Grade } \\
\hline grade I & 1.00 & & 1.00 & \\
\hline grade II & $2.28(0.55-9.44)$ & 0.256 & $2.1(0.51-8.72)$ & 0.306 \\
\hline grade III & $8.89(1.91-41.3)$ & $0.005^{\mathrm{a}}$ & $2.87(0.56-14.8)$ & 0.208 \\
\hline \multicolumn{5}{|c|}{ Initial Management } \\
\hline STR & 1.00 & & 1.00 & \\
\hline $\mathrm{STR}+\mathrm{RT}$ & $1.21(0.56-2.59)$ & 0.623 & $1.82(0.78-4.27)$ & 0.165 \\
\hline GTR & $0.62(0.27-1.39)$ & 0.244 & $0.57(0.21-1.52)$ & 0.260 \\
\hline $\mathrm{GTR}+\mathrm{RT}$ & $0.48(0.17-1.34)$ & 0.163 & $0.70(0.23-2.09)$ & 0.519 \\
\hline \multicolumn{5}{|l|}{ GTR vs STR } \\
\hline STR & 1.00 & & 1.00 & \\
\hline GTR & $0.50(0.28-0.89)$ & $0.0161^{\mathrm{a}}$ & $0.40(0.21-0.74)$ & $0.0027^{\mathrm{a}}$ \\
\hline \multicolumn{5}{|c|}{ Radiation after STR } \\
\hline STR alone & 1.0 & & 1.00 & \\
\hline STR and RT & $1.21(0.56-2.59)$ & 0.62 & $1.79(0.76-4.2)$ & 0.178 \\
\hline \multicolumn{5}{|c|}{ Radiation after GTR } \\
\hline GTR alone & 1.00 & & 1.00 & 0.618 \\
\hline GTR and RT & $0.81(0.31-2.11)$ & 0.67 & $1.30(0.46-3.65)$ & $0.0022^{\mathrm{a}}$ \\
\hline \multicolumn{5}{|c|}{ GTR vs STR + RT } \\
\hline $\mathrm{STR}+\mathrm{RT}$ & 1.00 & & 1.00 & \\
\hline GTR & $0.50(0.25-1.0)$ & $0.046^{\mathrm{a}}$ & $0.32(0.15-0.69)$ & \\
\hline
\end{tabular}

OS = overall survival; PFS = Progression Free Survival; HR = Hazard Ratio; $\mathrm{CI}=$ Confidence Interval; $\mathrm{WHO}=$ World Health Organization; STR $=$ Subtotal resection; GTR $=$ Gross total resection; $\mathrm{RT}=$ Radiotherapy ${ }^{a}$ Statistically significant $\mathrm{p}$ value

Patients with GTR alone had a better median progression-free survival (64 months) compared with those treated with STR and radiotherapy (31 months) $(\mathrm{p}=0.046)$.

\section{Overall survival}

The overall median survival was 90 months. Univariate analysis is shown in Table 2. Median survival was significantly different by age ranges with median survival of 62 months, 95 months, 138 months and 92 months for patients up to 6 years old, 7 to 17,18 to 50 and more than 50 years old, respectively.

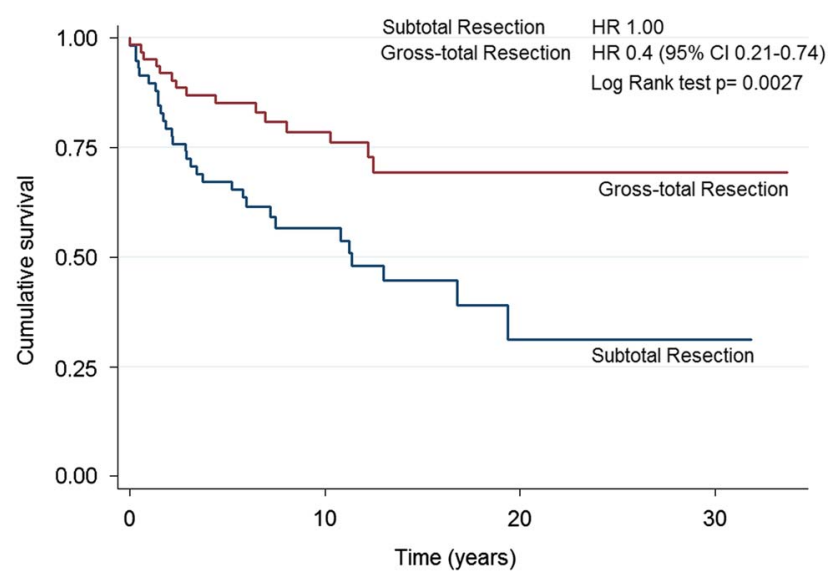

Figure 2: Overall survival of 129 patients with ependymoma (excluding myxopapillary) diagnosed in Alberta from 1975 to 2007, according to extent of initial resection.

$H R=$ Hazard Ratio; $\quad C I=$ Confidence $\quad$ Interval $; \quad S T R=$ Subtotal resection; $G T R=$ Gross total resection; $R T=$ Radiotherapy

Patients with spinal tumors lived a median of 127 months compared with 86 months for infratentorial and 75 months for patients with supratentorial tumors $(\mathrm{p}=$ not significant). When dichotomizing patients by spinal vs cerebral location (supratentorial and infratentorial tumors together) the difference in survival was suggestive but not statistically significant $(p=0.08)$. Patients with grade I tumors lived a median of 123 months compared with 90 months and 78 months for patients with grade II and III tumors, respectively but the differences were not statistically significant $(\mathrm{p}>0.2)$.

We observed a statistically significant difference in overall survival between patients receiving GTR versus STR with median OS of 123 months and 79 months, respectively $(\mathrm{p}=0.0027)$ (Figure 2). In this series the addition of radiotherapy to STR or GTR did not improve overall survival $(\mathrm{p}=0.178$ and $\mathrm{p}=0.618$, respectively). Furthermore, those with GTR had significantly improved median overall survival (122 months) as compared with patients who had STR and radiotherapy $(82$ months $[\mathrm{p}=0.0022)$ (Figure 3).

In multivariate analysis which included age, location, grade and extent of resection, only GTR was independently associated with an improvement in progression-free survival. An independent prognostic factor was not identified for overall survival (Table 3).

\section{DiscuSSION}

To our knowledge, this is the first population based analysis of patients with ependymoma including adults and children in Canada without any age limitation. This study included 158 patients with 29 tumors classified as myxopapillary ependymoma. The remaining 129 patients were mostly adult patients (63\%) usually with either infratentorial $(52 \%)$ or spinal tumors $(32 \%)$. Most patients had grade II lesions (82\%) and a similar proportion of patients had GTR versus STR ( $48 \%$ to $45 \%$ ). Amirian et al. ${ }^{14}$ published a large American retrospective review from 1973-2007 and reported, similar to our study, that the majority of were adults (71\%) with grade II $(88 \%)$ lesions similarly distributed throughout the CNS.

When analyzing our data to identify prognostic factors in patients with ependymoma, age was significant in univariate 


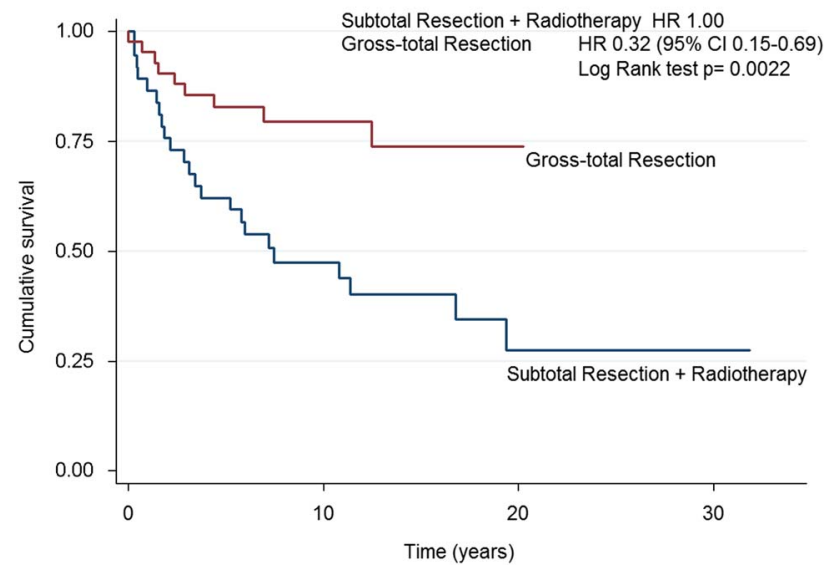

Figure 3: Overall survival of 129 patients with ependymoma (excluding myxopapillary) diagnosed in Alberta from 1975 to 2007 comparing subtotal resection followed by radiotherapy and gross-total resection. HR: Hazard Ratio, CI: Confidence Interval, STR: Subtotal resection, GTR: Gross total resection, RT: Radiotherapy

analysis for both progression-free and overall survival but was not an independent prognostic factor. Similar to other reports, we observed a bimodal association of age with death as both the youngest patients and those over the age of 50 had the worst prognosis. ${ }^{12,14}$ However, tumor location was not associated with better overall survival in our series. Patients with anaplastic ependymomas had worse PFS compared with those ependymomas grade I, but histological grade was not associated with OS in our study. However, other series have showed the prognostic value of both location and tumor anaplasia., ${ }^{3,11,12}$

Gross-total resection has been identified as a prognostic factor in many ${ }^{13-15,16-20}$ but not all pediatric and adult ependymoma series. ${ }^{21-23}$. In our study, GTR was associated with statistically significant improved PFS and OS compared with STR in univariate analysis but this did not hold up in multivariable analysis. However, the relationship between extent of surgery and survival is inconsistent within the literature. Our results corroborate the findings of Reni et al. ${ }^{24}$ who observed that GTR was associated with improved progression-free but not overall survival but not those of Amirian et al. ${ }^{14}$ who identified GTR as an independent prognostic factor for overall survival. Importantly, the definition of GTR varies depending on whether surgical opinion or a specific postoperative imaging modality is used. Regardless, maximal safe resection continues to be the standard of care.

One of the goals of this study was to analyze if the addition of radiotherapy to patients with subtotal resection could improve PFS/OS to levels similar to gross-total resection. In our series, postoperative radiotherapy after STR did not compensate for suboptimal surgery. Specifically, overall survival in patients with GTR was statistically superior compared with patients who had STR followed by radiotherapy. In a recently published retrospective review that included 348 patients who underwent STR of spinal cord ependymomas, the addition of radiotherapy was associated with prolonged progression-free survival $(p=0.047)$ but not overall survival. ${ }^{3}$ In another series of 88 patients with spinal ependymomas the addition of RT to GTR or STR did not improve progression-free or overall survival..$^{25} \mathrm{~A}$ subanalysis of 193 children with infratentorial tumors by McGuire et al. ${ }^{7}$ showed that postoperative radiotherapy improved survival $(p=0.033)$ but the extent of surgery in these patients was not reported. A review of 45 patients with posterior fossa ependymomas found that progression-free survival was similar between patients treated with GTR and STR followed by radiotherapy. However, in univariate analysis, the addition of RT to GTR improved PFS ( $p=0.018)$ without an effect in overall survival. ${ }^{26}$ Also, Amirian et al. ${ }^{14} \mathrm{com}$ pared extent of surgery with and without surgery in a manner similar to our study and reported that the addition of radiotherapy to less than GTR did not improve survival. A randomized control trial could assess the role of radiotherapy on outcome in patients with ependymoma. However, such a study may be difficult given that this is a rare tumor and a clinical trial randomization process would need, at a minimum, to control for age, tumor location, histological grade and extent of initial surgical resection.

The limitations of this study are those common to registry-based studies. Incomplete report or coding errors are possible. The pathologic classification was by report only in most cases, with a minority of cases, where the pathology report did not allow initial assignment into one of the diagnostic categories, requiring formal pathology review. Although little has changed in the histopathologic guidelines for classification of ependymomas over the time period of the study, it is possible that formal pathology review for every case may have changed some diagnoses. The extent of resection was based on the surgeon's intraoperative impression in about one third of the cases where radiological confirmation was not possible. This is particularly true for patients who had surgery during the early

Table 3: Multivariate analysis for PFS and OS of 129 patients with ependymoma (excluded myxopapillary) diagnosed in Alberta between 1975 and 2007

\begin{tabular}{l|c|c|c|c}
\hline $\begin{array}{l}\text { Variable } \\
\text { included }\end{array}$ & $\begin{array}{c}\text { PFS HR } \\
\mathbf{9 5 \%} \text { CI) }\end{array}$ & $\begin{array}{c}\text { PFS } \\
\text { p-value }\end{array}$ & $\begin{array}{c}\text { OS HR } \\
\mathbf{9 5 \%} \text { CI) }\end{array}$ & $\begin{array}{c}\text { OS } \\
\text { p-value }\end{array}$ \\
\hline Age range & $0.91(-7.39-19.92)$ & 0.365 & $0.38(-0.55-0.81)$ & 0.705 \\
\hline Location & $1.55(-4.86-40)$ & 0.123 & $*$ & \\
\hline WHO Grade & $-0.99(-53.59-17.98)$ & 0.326 & $*$ & \\
\hline GTR & $2.59(9.13-68.4)$ & $0.011^{\mathrm{a}}$ & $1.36(-10.13-54.2)$ & 0.177 \\
\hline
\end{tabular}

CI: Confidence Interval, WHO: World Health Organization, GTR: gross-total resection, OS: overall survival, PFS: Progression

Free Survival, HR: Hazard Ratio

*Variable not included as not statistically significant in univariate analysis

${ }^{a}$ Statistically significant $\mathrm{p}$ value 
years of the study period. We recognize surgeons are not reliable at estimating degree of resection, and in more recent years the accuracy of this evaluation has improved with advances in neuro-imaging.

This series describes the characteristics and outcomes of unselected patients diagnosed with ependymoma. In our study, the addition of radiotherapy to STR did not improve overall survival compared with patients with GTR. We highlight the importance of maximum safe resection with GTR identified as the main significant prognostic factor for better patient outcome.

\section{Disclosures}

JE does not have anything to disclose.

\section{REFERENCES}

1. Louis DN, Ohgaki H, Wiestler OD, et al. The 2007 WHO classification of tumours of the central nervous system. Acta Neuropathol. 2007;114(2):97-109.

2. McGuire CS, Sainani KL, Fisher PG. Incidence patterns for ependymoma: A surveillance, epidemiology, and end results study. J Neurosurg. 2009;110(4):725-9.

3. Oh MC, Ivan ME, Sun MZ, et al. Adjuvant radiotherapy delays recurrence following subtotal resection of spinal cord ependymomas. Neuro Oncol. 2013;15(2):208-15.

4. Vaidya K, Smee R, Williams JR. Prognostic factors and treatment options for paediatric ependymomas. J Clin Neurosci. 2012; 19(9):1228-35.

5. Wright KD, Gajjar A. Current treatment options for pediatric and adult patients with ependymoma. Curr Treat Options Oncol. 2012;13(4):465-77.

6. Koshy M, Rich S, Merchant TE, Mahmood U, Regine WF, Kwok Y. Post-operative radiation improves survival in children younger than 3 years with intracranial ependymoma. J Neurooncol. 2011;105(3):583-90.

7. McGuire CS, Sainani KL, Fisher PG. Both location and age predict survival in ependymoma: A SEER study. Pediatr Blood Cancer. 2009;52(1):65-9.

8. Venkatramani R, Dhall G, Patel M, et al. Supratentorial ependymoma in children: To observe or to treat following gross total resection? Pediatr Blood Cancer. 2012;58(3):380-3.

9. Benesch M, Weber-Mzell D, Gerber NU, et al. Ependymoma of the spinal cord in children and adolescents: A retrospective series from the HIT database. J Neurosurg Pediatr. 2010;6(2):137-144.

10. Jung J, Choi W, Ahn SD, et al. Postoperative radiotherapy for ependymoma. Radiat Oncol J. 2012;30(4):158-64.

11. Swanson EL, Amdur RJ, Morris CG, et al. Intracranial ependymomas treated with radiotherapy: Long-term results from a single institution. J Neurooncol. 2011;102(3):451-7.
12. Armstrong TS, Vera-Bolanos E, Bekele BN, Aldape K, Gilbert MR. Adult ependymal tumors: Prognosis and the M. D. Anderson cancer center experience. Neuro Oncol. 2010;12(8):862-70.

13. Cage TA, Clark AJ, Aranda D, et al. A systematic review of treatment oucomes in pediatric patients with intracranial ependymomas. J Neurosurg Pediatr. 2013;11(6):673-81.

14. Amirian ES, Armstrong TS, Aldape KD, Gilbert MR, Scheurer ME. Predictors of survival among pediatric and adult ependymoma cases: A study using surveillance, epidemiology, and end results data from 1973 to 2007. Neuroepidemiology. 2012; 39(2):116-24

15. Reni M, Gatta G, Mazza E, Vecht C. Ependymoma. Crit Rev Oncol Hematol. 2007;63(1):81-9.

16. Merchant TE, Li C, Xiong X, Kun LE, Boop FA, Sanford RA. Conformal radiotherapy after surgery for paediatric ependymoma: A prospective study. Lancet Oncol. 2009;10(3):258-66.

17. Duffner PK, Krischer JP, Sanford RA, et al. Prognostic factors in infants and very young children with intracranial ependymomas. Pediatr Neurosurg. 1998;28(4):215-22.

18. Kawabata Y, Takahashi JA, Arakawa Y, Hashimoto N. Longterm outcome in patients harboring intracranial ependymoma. J Neurosurg. 2005;103(1):31-7.

19. Oya N, Shibamoto Y, Nagata Y, Negoro Y, Hiraoka M. Postoperative radiotherapy for intracranial ependymoma: Analysis of prognostic factors and patterns of failure. J Neurooncol. 2002; 56(1):87-94.

20. Metellus P, Barrie M, Figarella-Branger D, et al. Multicentric French study on adult intracranial ependymomas: Prognostic factors analysis and therapeutic considerations from a cohort of 152 patients. Brain. 2007;130(Pt 5):1338-49.

21. Guyotat J, Signorelli F, Desme S, et al. Intracranial ependymomas in adult patients: Analyses of prognostic factors. J Neurooncol. 2002;60(3):255-68.

22. Conter C, Carrie C, Bernier V, et al. Intracranial ependymomas in children: Society of pediatric oncology experience with postoperative hyperfractionated local radiotherapy. Int J Radiat Oncol Biol Phys. 2009;74(5):1536-42.

23. Moreno L, Bautista FJ, Zacharoulis S. Outcome of teenagers and young adults with ependymoma: The Royal Marsden experience. Childs Nerv Syst. 2009;25(9):1047-52.

24. Reni M, Brandes AA, Vavassori V, et al. A multicenter study of the prognosis and treatment of adult brain ependymal tumors. Cancer. 2004;100(6):1221-9.

25. Lee SH, Chung CK, Kim CH, et al. Long-term outcomes of surgical resection with or without adjuvant radiation therapy for treatment of spinal ependymoma: a retrospective multicenter study by the Korea Spinal Oncology Research Group. Neuro Oncol. 2013; 15(7):921-9.

26. Rogers L, Pueschel J, Spetzler R, et al. Is gross-total resection sufficient treatment for posterior fossa ependymomas? J Neurosurg. 2005;102(4):629-36. 